\title{
As Construtoras Brasileiras e o Processo de Integração Regional na América do Sul
}

\section{Patrícia Mara Cabral de Vasconcellos}

Universidade Federal de Rondônia (Unir); Porto Velho-RO, Brasil.

Email:pmcvasconcellos@gmail.com

\begin{abstract}
Resumo: O objetivo do artigo é compreender o papel das construtoras brasileiras no processo de integração da América do Sul. Presentes no mercado sul-americano desde a década de 70, no entanto, é no contexto da Iniciativa para a Integração da Infraestrutura Regional Sul-Americana (IIRSA) e durante o governo Lula que as transnacionais brasileiras assumem um papel de destaque na estratégia da Política Externa Brasileira (PEB). Para compreender os dilemas e os interesses da relação Estado-empresas demarcam-se as diferenças entre o processo de internacionalização da década de 70 e o atual, bem como as transformações ideológicas que compõem o paradigma da PEB e os mecanismos de apoio governamental. A metodologia é baseada em pesquisa qualitativa e bibliográfica, bem como em entrevistas e pesquisa nos arquivos do Itamaraty. Nota-se que as construtoras são elementos de uma política estratégica na qual o Brasil objetiva interesses que estão além do discurso de integração regional. do Sul.

Palavras-chave: Construtoras, Política Externa, Integração, América
\end{abstract}

\section{Las constructoras brasileñas y el proceso de integración regional en América del Sur}

Resumen: Este trabajo tiene como objetivo comprender el papel de las empresas constructoras brasileñas en el proceso de integración de América del Sur. Presentes en el mercado de América del Sur desde los años 70, sin embargo, es en el contexto de la Iniciativa para la Integración de la Infraestructura Regional Sudamericana (IIRSA) y durante el gobierno de Lula que las transnacionales brasileñas asumen un papel importante en la estrategia de la Política Exterior de Brasil (PEB). Para entender los dilemas y los intereses de la relación entre empresas y Estado se destacan las diferencias entre el proceso de internacionalización de los años 70 y el actual, así como las transformaciones ideológicas que conforman el paradigma de la PEB y los mecanismos de apoyo gubernamentales. La metodología está basada en investigación cualitativa y bibliográfica, así como en entrevistas e investigación en los archivos del Ministerio de Relaciones Exteriores (Itamaraty). Se destaca que las constructoras son elementos de una política estratégica en la que Brasil objetiva intereses que están más allá del discurso de integración regional.

Palabras clave: Constructoras, Política Exterior, Integración, América del Sur. 


\title{
The Brazilian construction Companies and the process of regional integration in South America
}

\begin{abstract}
The paper's purpose is to understand the role of Brazilian construction Companies in the integration process in South America. The construction Companies operating in the South American market are present since the 70s, however, it is in the context of the Initiative for the Integration of Regional Infrastructure in South America (IIRSA) and during Lula's government, that the Brazilian transnationals assume a role in Brazilian Foreign Policy's (PEB) strategy. To understand the dilemmas and the interests between state and enterprises, the differences between the internationalization process of the 70s and the current are outlined, as well as the ideological transformations that constitute the paradigm of PEB and the mechanisms of government support. The methodology is based on qualitative research, biographical research, as well as interviews and research in the archives of the Foreign Relations Ministry (Itamaraty). The conclusion is that construction companies are elements of a strategic policy, in which Brazil has interests that are beyond the discourse of regional integration.
\end{abstract}

Key words: Construction Company, foreign policy, Integration, South America.

$* * *$

\section{Introduçao}

As construtoras brasileiras iniciam o seu processo de internacionalização na década de 1970, no entanto, a partir de 2002, a inserção e a consolidação no mercado externo apresentam características que apontam para o vínculo entre o interesse econômico da empresa e os objetivos do Estado brasileiro. Assim, delineia-se uma politica externa que incorpora o processo de internacionalização de empresas como um de seus fundamentos e, portanto, instrumentaliza as empresas para alcançar os interesses nacionais. A expansão das construtoras brasileiras na América do Sul, nos anos 2000, pode ser lida como parte resultante da aliança de interesses entre Estado e empresas.

O processo de internacionalização das empresas brasileiras de engenharia e construção não é um processo novo e pode ser caracterizado por, pelo menos, duas fases. A fase inicial, na década de 1970 e a fase atual, a partir dos anos 2000. As distinções visualizadas entre os dois períodos referem-se às motivações empresariais, a forma do apoio governamental e, em especial, ao papel que as empresas assumem frente aos interesses de política externa do Estado brasileiro na América do Sul. De fato, na fase atual, mais do que agentes econômicos, as empresas transnacionais ${ }^{1}$ brasileiras de construção exercem uma diplomacia tríade ${ }^{2}$ que busca consolidar os interesses e a liderança política do Brasil no processo de integração sul-americana. Para elucidar tal afirmativa, primeiramente apresentam-se as caraterísticas que modelam o processo de internacionalização das construtoras nas duas fases propostas. 
Posteriormente, apresenta-se a visão brasileira sobre a internacionalização das empresas dentro do paradigma da política externa denominado de "novo desenvolvimentismo". Nesse paradigma entende-se que é preciso diversificar as exportações e atuar em novos mercados. Por consequência, o Estado defende a internacionalização de suas empresas e assume a responsabilidade de prestar o apoio necessário para que elas possam competir no mercado global. A concepção novo-desenvolvimentista propõe uma nova combinação entre Estado e mercado, em que ambos, são caracterizados como fortes (Sicsú; Paula; Michel, 2007). Cervo (2009) afirma que a internacionalização das empresas tornou-se viável, nesse período, mental e materialmente por três razões: a primeira refere-se à própria capacidade da empresa de projetar-se no mercado externo, com capital e produtividade; a segunda, a maturação da empresa em termos gerenciais e de how-know; e, por fim, o apoio do Estado, derivado de uma mudança de mentalidade que encontra referência no Estado logístico. Desse modo, a internacionalização torna-se necessária e a diplomacia responde as demandas do desenvolvimento nacional não somente na ótica de seus agentes de Estado, mas, também, na atuação de seus agentes de mercado.

No terceiro ponto apresentam-se os interesses e os mecanismos utilizados pelo governo brasileiro para impulsionar a internacionalização das empresas de engenharia no processo de integração sul-americano. Em especial, visualiza-se o apoio fornecido através do financiamento do BNDES e da diplomacia tradicional. Com base nos dados fornecidos pelo BNDES sobre a exportação de serviços será possível perceber a importância do Estado como financiador das obras. A diplomacia tradicional representa a construção formal da imagem brasileira, nos países vizinhos, por meio da relação tríade.

Conclui-se, de modo geral, que a relação entre as transnacionais, o Brasil e os países vizinhos é composta por questões e interesses que ultrapassam o discurso de bem estar e desenvolvimento dos povos por meio da integração regional. O Brasil concebe por meio da consolidação das empresas brasileiras na América do Sul como um modo de exercer influência política e econômica na região. No caso das construtoras, o apoio fornecido pelo governo brasileiro surge como prerrogativa para ajudar no desenvolvimento regional, sendo respaldado por acordos de integração regional, como a Iniciativa para a Integração de Infraestrutura Regional Sul Americana.

\section{Da década de 70 aos anos 2000: a presença das construtoras brasileiras na regiao sul-americana}

As empresas de engenharia brasileiras tiveram sua origem na década de 1940 e durante os anos de 1950 e 1960 adquiriram experiência e se consolidaram no mercado interno, o que possibilitou a sua expansão para o mercado externo nas décadas seguintes. Contudo, segundo Ferraz Filho 
(1981), a consolidação no mercado interno e a experiência administrativa acumulada foram variáveis necessárias, mas não suficientes para a internacionalização das empresas brasileiras.

No que se refere ao processo de internacionalização, as empresas de engenharia brasileiras iniciaram suas atividades na década de 1970. A empresa Mendes Júnior, por exemplo, foi a primeira a exercer atividades no exterior, construindo a hidrelétrica de Santa Isabel, na Bolívia, em 1969, e uma rodovia na Mauritânia, África, em 1975. A Odebrecht construiu, em 1979, a hidrelétrica de Charcani V, em Arequipa, Peru. A Camargo Corrêa participa da construção e montagem, em 1978, da usina de Guri, na Venezuela. A Gueiroz Galvão constrói a barragem de Paso San Severino, no Uruguai, em 1984. No mesmo ano, a Andrade Gutierrez inicia sua atuação internacional construindo a rodovia Epena-Impfondo-Dongou, no Congo e a rodovia Cochabamba-Chimaré e Yapacani-Guabirá, na Bolívia. Assim, os primeiros mercados das empresas brasileiras foram países da África e, principalmente, da América do Sul.

Para afirmar a partir de qual momento a política externa e a internacionalização das empresas de construção e engenharia possuem seus interesses alinhados é preciso aprofundar o debate. Assim, a análise deve atentar para as razões que motivam a empresa a decidir pela internacionalização em, pelo menos, dois pontos. Primeiro, de natureza econômica, refere-se aos objetivos da empresa como redução de custos, obtenção de tecnologia, acesso a recursos naturais e outros. Segundo, de natureza política, refere-se a fatores ou circunstâncias que facilitam o processo de internacionalização. Cita-se como exemplo, o apoio do governo e do componente diplomático. Dessa forma, frisam-se as oportunidades e os instrumentos visualizados pelas empresas no processo de decisão. Na medida em que os pontos relacionados à natureza econômica e à natureza política se aproximam é possível delinear em que medida os interesses se conjugam.

Na primeira fase da internacionalização (1970 a 1990), as variáveis explicativas para a internacionalização das construtoras são basicamente: a consolidação no mercado interno, a desaceleração ou crise do mercado doméstico, a dinâmica proativa da empresa e a diversificação do mercado com redução dos riscos. O apoio do governo ocorre, principalmente, mediante pressão realizada pelas construtoras aos órgãos do Estado. Assim, os mecanismos de apoio à internacionalização são resultado mais de iniciativas empresariais que necessitavam minimamente de um respaldo estatal do que de um projeto político econômico do Estado através das empresas. As motivações para a busca do mercado externo em específicas situações, nas quais se destacam a atuação da Mendes Jr na construção da ferrovia Baghdah-Akashat e da rodovia Expressway, no Iraque e a atuação da Odebrecht com a construção da Hidrelétrica de Capanda, em Angola, foram precedidas de apoio e interesse por parte do governo brasileiro.

Dentre as razões que possibilitaram o processo de internacionalização 
tem-se o argumento recorrente de que serviços de infraestrutura, realizados em território brasileiro nas décadas anteriores, permitiram que as empresas brasileiras adquirissem know-how em grandes obras, estando, portanto, capacitadas a competir no mercado externo. Outra razão apontada é a crise ou baixa demanda do mercado doméstico. Dentre os autores que compartilham desse argumento cita-se Iglesias e Veigas e, também, Ricupero. De acordo com Iglesias e Veigas (2002), no final do regime militar, na década de 1970, com o crescente endividamento do Estado, processo inflacionário e incapacidade do governo de continuar a financiar grandes obras públicas, as empresas percebem que o mercado doméstico não é atrativo, ou seja, há uma desaceleração nesse setor e as empresas veem-se pressionadas a buscar o mercado externo. Para Ricupero (informação verbal ${ }^{3}$ ), a experiência das empresas brasileiras com o início do processo de internacionalização é singular. O embaixador relata que em outros países como Coréia do Sul, Cingapura e, recentemente, a China, esta iniciativa, em geral, é fruto do sucesso das empresas e tem origem com o setor de manufaturados. No caso brasileiro, a internacionalização surge como uma alternativa de sobrevivência, sendo fruto das dificuldades, isto é, de uma retração do mercado interno.

Com um ponto de vista que diverge da perspectiva de que foi a crise interna no mercado de construções que impulsionou a internacionalização, citam-se autores como Viégas, Ferraz Filho e Campos. De acordo com Viégas (2009), a Mendes Júnior, por exemplo, pioneira no processo de internacionalização, já havia avaliado a redução dos riscos no mercado externo e teria buscado diversificar o mercado frente a uma redução da demanda. Para a Mendes Júnior, segundo Attuch e Mendes (2008), a internacionalização era uma forma de diversificar riscos e de minorar a dependência do cliente público (Estado) evitando-se a dependência e a inadimplência. Ferraz Filho (1981), por sua vez, aponta que o argumento de retração da demanda para a internacionalização das empresas brasileiras não se sustenta. Baseando-se nos argumentos de Coutinho e Reichstul ${ }^{4}$, o autor conclui que apesar da diminuição nos investimentos públicos, o setor elétrico assegurou o ritmo de crescimento e que os investimentos em transporte somente se retraem a partir de 1976, o que manteria o setor de construção pesada ou o setor de obras públicas afastados da crise.

Campos (2010), também, considera que, no caso das empresas de engenharia e construção, não foi a baixa demanda no mercado interno que conduziu as empresas ao mercado externo. $\mathrm{O}$ autor afirma que no período do milagre econômico, na década de 70, ocorreu o auge dos serviços de infraestrutura no país. Considera que as empresas de engenharia buscaram o mercado externo porque havia a possibilidade de conseguir lucros maiores e porque o empresariado brasileiro já havia conseguido se articular internamente para conseguir o apoio necessário à sua internacionalização. Sobre o apoio governamental, o autor relata que havia o apoio do Itamaraty e eram fomentadas políticas de apoio à internacionalização para esse setor, como o Decreto-Lei 141-8/75 que tratava do direito de as empresas reduzirem de seu lucro tributável os resultados com a venda de serviços no exterior (Campos, 
2010: 12). Neste caso, o papel do Estado teria sido fundamental. O Brasil promoveu políticas externas favoráveis, participou de projetos internacionais e possibilitou o financiamento direto (Campos, 2008).

Apesar das políticas mencionadas por Campos (2008), aponta-se que a diferença do apoio governamental no processo de internacionalização da década de 70 e dos anos 2000 está em sua amplitude e política regional e na capacidade do Brasil em agir como financiador. Para a América do Sul, por exemplo, a atuação do Brasil é tão somente de reação as demandas das construtoras e somente em obras de grande vulto, o que comparado a proposta atual com a IIRSA, por exemplo, é mínimo. No início da internacionalização houve o apoio do governo brasileiro, como componente estratégico, diante de um contexto específico que foi a crise de energia.

Diante dos choques do petróleo, o principal incentivo ao mercado externo foi destinado às empresas que pudessem atuar nos países produtores de petróleo, realizando a troca de serviços por esta matéria-prima. Entretanto, não se formulou uma política para a internacionalização das empresas brasileiras e sim uma política externa pragmática para a solução de uma demanda interna. O empenho diplomático do Estado brasileiro na atuação da Mendes Jr no Iraque, na década de 70 e $80^{5}$ e da Odebrecht em Angola em $1975^{6}$, configuram-se em uma política de troca de serviços de engenharia por petróleo. Inclusive, os contratos eram firmados tendo como modo de pagamento o sistema counter-trade ${ }^{7}$. Na América do Sul, houve a tentativa de negociação com a Venezuela, no entanto, este país exigia o pagamento em dólar, o que era inviável para o Brasil (Fares, 2007).

Assim, de modo geral, as demais iniciativas de conquista do mercado externo pelas construtoras brasileiras, nesse período, ocorreram desvinculadas de uma política de apoio governamental ou de política externa que tivesse como pauta o processo de internacionalização. $\mathrm{O}$ apoio diplomático teve por base o interesse nacional pelo recurso energético ou ocorreu de modo casuístico, estando presente somente em contratos considerados expressivos pelo governo brasileiro, evidenciando a ausência de mecanismos de apoio à internacionalização de suas empresas embasados em um planejamento de Estado sobre a relação entre transacionais e sua política externa.

Um vínculo incipiente entre projeção do Estado Brasileiro e internacionalização das empresas começa a se delinear a partir do processo de integração do MERCOSUL, década de 90, através da abertura da economia e com o abandono de uma visão negativa sobre a atuação das empresas transnacionais. Contudo, somente a partir dos anos 2000 é que a internacionalização passa a ser incorporada aos interesses do Estado. Com intuito de aprofundar esta afirmativa, propõese uma análise da visão da política externa brasileira sobre as empresas transnacionais. 


\section{As empresas transnacionaes na politica esterna brasileira}

Na perspectiva da política externa brasileira frente ao objetivo de desenvolvimento do país, do início da internacionalização das empresas brasileiras na década de 1970 aos dias atuais, a visão sobre as empresas transnacionais transformou-se. Inicialmente marcado por um conceito negativo de que as empresas prejudicavam o desenvolvimento autônomo dos países menos desenvolvidos, passou-se para uma concepção de que a inserção do país no mercado global, inclusive por meio das transnacionais, é incontestável e favorável ao desenvolvimento ${ }^{8}$.

Da década de 30 à década de 80, predominou na PEB o paradigma nacional desenvolvimentista, vigente na primeira fase da internacionalização das empresas brasileiras. Após 2002, há o resgaste de premissas desse paradigma com uma nova leitura conjuntural e estrutural através do neodesenvolvimentismo. Entre uma fase e outra, na década de 90, vivencia-se o paradigma neoliberal no qual as transnacionais, como agentes de mercado, podem ser protagonistas e ocupar o espaço de influência do Estado. Contudo, é no paradigma neodesenvolvimentista que a promoção da internacionalização de empresas passa a ser visto como uma dinâmica que contribui para o desenvolvimento nacional. O paradigma alia mercado e Estado e a internacionalização de empresas surge como um elemento chave. Preceitua-se que é necessário um Estado forte e um mercado forte para o desenvolvimento. Resgata, portanto, a importância concebida ao Estado nacional pelo paradigma nacionaldesenvolvimentista e o concilia com preceitos liberais de fortalecimento do mercado. De acordo com Toni (2013), o novo desenvolvimentismo é um meio termo entre o discurso do nacional desenvolvimentista e o consenso de Washington.

Cervo define o período novo desenvolvimentista utilizando-se do conceito de Estado logístico. Para Couto (2010), a diferença entre os termos expressa-se mais em função de marketing que de substância. O primeiro livra-se dos resquícios negativos que a denominação desenvolvimentista acarreta, evitando-se considerações pejorativas vinculadas ao discurso "terceiro-mundista" ou "ideológico". A denominação "logístico" evitaria debates desnecessários com setores conservadores da sociedade. Na visão de autor, o termo Estado logístico revela de modo coerente a forma como o governo conduz a nova estratégica, primando por um Estado que é mediador dos interesses dos diversos segmentos da sociedade e que incentiva e apoia a internacionalização das empresas brasileiras.

De toda forma, a proposta é de promover uma aliança nacional que permita competir internacionalmente. O Estado assume o papel de aliar-se ao mercado e à elite empresarial do país. Promove o investimento, reforça a política industrial e atua fortemente na promoção da redistribuição. Adota, comercial e economicamente, um modelo exportador onde busca a exportação de alto valor agregado e somada a 
uma nova política industrial. Com isso, o Estado defende a internacionalização de suas empresas e assume a responsabilidade de prestar o apoio necessário para que elas possam competir no mercado global.

No paradigma anterior, Estado neoliberal, há a ênfase na força e autonomia do mercado, sem necessidade de intervenção ou apoio do Estado. No Estado neoliberal ou Estado normal, a responsabilidade deste, com relação ao desenvolvimento, é mínima (Cervo,2008). A premissa é o fortalecimento das funções do mercado e a redução do papel do Estado. O paradigma neoliberal na política externa favorece a abertura do mercado, mas a internacionalização ainda é uma decisão fortemente empresarial.

De forma geral, o "novo" incorporado ao termo implica em uma discussão sobre o modelo político-econômico, princípios de gestão do Estado e modo de inserção no cenário internacional. Com relação a este, a partir de 2002, destaca-se o processo de reformulação e implantação da Política Exterior do Brasil, através de um discurso que enfatiza a cooperação Sul-Sul, o processo de integração regional e a exportação de um modelo de desenvolvimento ambiental.

Mesmo com contradições, o novo desenvolvimentismo aponta para uma política externa onde o Brasil busca exercer uma liderança no cenário internacional diversificando relações econômicas e comerciais, propagando uma ideologia de desenvolvimento não-hegemônico ou focado na democratização das relações, na primazia da defesa dos aspectos sociais (inclusão) e na preservação ambiental.

Por mais que no novo-desenvolvimentismo enfatize-se o caráter internacionalista favorecendo a expansão das empresas transnacionais brasileiras, no caso do Brasil, não se deve exclui outras variáveis explicativas para a expansão das transnacionais, que incluem fatores como a melhora na capacidade de financiamento das transnacionais brasileiras, a disponibilidade de recursos externos (baixa taxa de juros e maior liquidez global), a alta no preço das commodities, a política anticíclica do governo, o maior crescimento da economia brasileira e a iniciativas de apoio do governo à internacionalização (Caseiro, 2013). Sublinha-se, tão somente, como a construção de uma vertente política neodesenvolvimentista respaldou definidas ações na expectativa de determinados resultados.

Oliva (2010), em sua tese de doutorado sobre as bases do novo desenvolvimentismo, avalia que, assim como no nacionaldesenvolvimentismo, a política externa no "novo" é orientada conforme a concepção e objetivos do desenvolvimento nacional; contudo, possui como característica marcante o fato do social ser um dos eixos estruturantes e, mesmo que possua elementos nacionalistas, é mais internacionalista que a proposta desenvolvimentista anterior. Outra 
diferença importante é que a dinamização da economia e comércio pela política externa não ocorre via substituição de importações, mas, sim, pela diversificação das exportações e atuação em novos mercados.

Atenta-se para o fato que autores como Cardoso e Miyamoto (2012), Vigevani e Cepaluni (2007) e Tastsch (2011) discutem as semelhanças da política externa brasileira, durante o governo Geisel, na década de 70, e o governo Lula. Mesmo com conjunturas distintas, algumas aproximações são apontadas em ambos os períodos. Exemplos: a aproximação com a África, a diplomacia ativa, a diversificação de parcerias e uma estratégia realista no sistema internacional.

Em termos de objetivo de política externa, em linhas gerais, os governos de Lula e Geisel se aproximam. Todavia, o papel do Estado e das empresas, com as comparações descritas acima, tornam o planejamento e o respaldo teórico, essencialmente, distintos. O caráter internacionalista e pró-mercado incutem uma nova perspectiva de projeção, atuação e contribuição do país no sistema internacional.

Cervo (2008) analisa três pontos relacionados à política externa que refletem a mudança de paradigma no governo Lula. Primeiro, o projeto de integração da América do Sul através da integração produtiva da infraestrutura, reforçando as relações com o entorno geográfico. Segundo, a internacionalização da economia, anteriormente mencionada, atribuindo ao Estado uma função estratégica ao direcionar e possibilitar oportunidades para consolidação e ampliação do comércio. Neste ponto, incorpora-se a política de internacionalização de empresas brasileiras. Por último, a opção de enfatizar a relação com os países em desenvolvimento ou emergentes objetivando formar coalizões capazes de resistência aos impulsos hegemônicos.

A consolidação do novo desenvolvimentismo como uma estratégia viável para o desenvolvimento e para inserção do Brasil no cenário internacional representa um desafio para a diplomacia brasileira. A relação entre empresas transnacionais com os Estados, por exemplo, podem refletir percepções distintas de governança e política externa. Embora o adensamento das relações comerciais entre os países vizinhos seja um fator que colabora para o desenvolvimento, os investimentos brasileiros na região nem sempre são vistos de forma positiva. De acordo com Almeida (2009), a governança deve ser pensada quanto aos procedimentos de negociação e quanto aos resultados. O Brasil que defende os espaços de discussão para os países em desenvolvimento e o fortalecimento das instâncias multilaterais deve estar atento para não impor soluções prontas para o desenvolvimento da região sul-americana, reavivando o discurso do imperialismo presente durante o paradigma do nacional-desenvolvimentismo sobre as empresas transnacionais. A seguir, apontam-se alguns dos interesses e a forma de atuação do Estado Brasileiro no processo de internacionalização das empresas de construção. 


\section{Interesses em pauta: o apoio do governo a exportaçao de serviços de engenharia}

Dois fatores se aliam na conjunção de interesses entre Estado e empresas na América do Sul. De um lado, para o Brasil, a região é prioritária para o desenvolvimento e estreitamento das relações regionais e bilaterais. De outro lado, para as construtoras, o mercado sul americano é o principal e primeiro mercado de atuação. Segundo Sennes et al. (2007), para os serviços de infraestrutura, a região sul-americana é um mercado prioritário na estratégia de internacionalização.

Na perspectiva do Estado de origem da empresa, Gilpin (2002) aponta alguns pontos em que o interesse do Estado pode confluir com o das empresas transnacionais. Contudo, ressalta que nem sempre a convergência ocorre. Por vezes, a estratégia do governo em tornar as empresas um instrumento de seus interesses não encontra correspondência possível nos objetivos das corporações, ou seja, mesmo com envolvimento estatal, as empresas podem considerar o risco alto e não assumirem o compromisso. A construção de hidrelétricas no Peru, por exemplo, contempla interesses brasileiros e, em 2011, apesar do apoio diplomático e financeiro do Brasil, a Odebrecht desiste do empreendimento apresentando uma carta subscrita pelo diretor da empresa no Peru, Erlon Arfelli, em que relata a desistência de

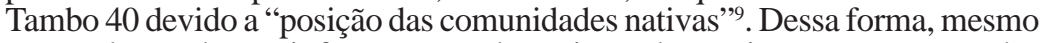
com a demanda por infraestrutura da região sul-americana e a atuação das empresas brasileiras sendo considerada estratégia pelo Brasil, é preciso considerar que podem existir outras oportunidades de menor risco para a empresa e a relação tríade não se estabelecer.

Um dos interesses do Estado na atuação das transnacionais, segundo Gilpin, condiz com o fato das empresas possuírem acesso a matériasprimas ou produtos básicos e o Estado através delas poder garantir o fornecimento desses bens ou ao menos restringir o seu aumento de preço em sua situação de crise ou conflito. No caso brasileiro, nota-se que em 2006, 67,2\% do total dos ativos das vinte maiores multinacionais brasileiras, corresponde a empresas vinculadas a insumos básicos e matérias primas, como é o caso da Companhia Vale do Rio Doce (CVRD) e da Petrobrás (FDC, 2007). As empresas de construção possuem atividades relacionadas com estas empresas, dada a própria construção de infraestrutura necessária para a operação das mesmas. Além disso, o acesso a recursos naturais também ocorre com a construção de grandes obras de infraestrutura como é o caso das hidrelétricas.

Outro interesse, em especial com relação às empresas industriais e de serviços é que por meio do investimento direto externo, o Estado pode manter a sua posição relativa nos mercados mundiais. O Estado mantém a sua participação no mercado mundial mesmo com outras economias em expansão, o que permite manter a sua capacidade de competição. Além disso, a expansão das transnacionais é favorável aos interesses do balanço 
de pagamento do país, já que são produtoras de divisas. Estes recursos são fonte importante de manutenção de outras formas de poder e influência global. No caso do Brasil, Além da expressividade no PIB ${ }^{10}$, o setor de serviços, em especial o de engenharia, é um dos poucos setores que geram superávit na balança de pagamentos.

As empresas, também, podem ser um instrumento do desenvolvimento econômico global e um mecanismo para difusão da ideologia da livre iniciativa. Neste ponto, o autor parte da análise que a expansão das empresas norte-americanas na década de 70 poderia ser um instrumento particularmente interessante contra o comunismo. De certa forma, há um componente ideológico na presença das construtoras brasileiras na região sul-americana, já que o Brasil relaciona a sua presença e de suas empresas ao processo de integração regional. A integração é um compromisso que deve ser firmado entre as partes na ênfase da promoção do espaço sul-americano. Com isso, a liderança do Brasil se fortalece frente à presença dos Estados Unidos e da China, por exemplo.

No caso brasileiro das empresas transnacionais de construção e engenharia estes interesses apontados por Gilpin consolidam-se por meio do apoio do Estado. Diferentemente da década de 70, nos anos 2000 há uma defesa das transnacionais no discurso da política externa brasileira. Os incentivos ao mercado externo passam a ser explícitos, ainda que, na prática, governo e empresas tenham dificuldades em executá-los. No caso das construtoras, dois mecanismos de apoio se destacam: (1) com o aporte financeiro - BNDES e a (2) atuação do corpo diplomático.

Na atualidade, o Banco Nacional de Desenvolvimento Econômico Social (BNDES) assume a função de banco financiador. Na década de 70, o BNDE não dispunha de recursos. A partir da última década, uma conjuntura no cenário externo permitiu a formação de uma capacidade de poupança que se aliou a uma política governamental do Brasil de desenvolvimento de comércio e de infraestrutura, em seu entorno geográfico.

Assim, no final da década de 90, o banco centrava-se na capacidade de financiamento e direcionamento das suas atividades para o apoio à exportação. Em 1997, o BNDES iniciou o apoio à exportação de serviços com a transformação da linha Finamex em BNDES-Exim. A mudança possibilitava, além do financiamento de bens de capital, a exportação de serviços de engenharia e de outros bens (eletrônico, alimentos e outros) (Catermol, 2005). Tratava-se de uma linha de financiamento destinada a exportações de alto valor agregado e que permitia financiamento combinado com outras agências de fomento. As primeiras operações foram destinadas ao financiamento de exportações de bens e serviços brasileiros de obras realizadas no Equador. Para Carvalho (2011), o principal beneficiário dessa mudança foi o setor de engenharia.

O apoio à internacionalização das empresas brasileiras, também, foi enfatizado em 2002, quando o Banco Nacional de Desenvolvimento 
Econômico Social (BNDES) aprovou uma linha de financiamento específica para incentivar a atuação das empresas brasileiras no mercado internacional, via exportação. Naquele ano, o Estatuto do BNDES foi alterado visando autorizar o financiamento de projetos de investimento direto no exterior. Com a alteração do Estatuto, foi criado o Programa de Apoio a Investimentos de Empresas Brasileiras de Capital Nacional no Exterior. Em 2005, foram aprovadas as normas de financiamento de IDE. As empresas beneficiárias destas normas são aquelas de capital nacional que atuam em atividades industriais ou na área de engenharia, com estratégia de internacionalização em longo prazo (Fiocca, 2006).

Em 2009, com o objetivo de diversificar e facilitar as fontes de recursos para os financiamentos, o BNDES abriu um escritório em Montevidéu, em agosto, com o intuito de reforçar as operações do Brasil com os países vizinhos e uma subsidiária em Londres, inaugurada em novembro. De acordo com Novoa (2009), essas iniciativas significam um processo em que se almeja compatibilizar política externa com política de integração regional por meio do processo de expansão de capitais (Novoa, 2009: 197). Em dezembro de 2013 foi inaugurado um escritório do BNDES em Johanesburgo, África do Sul.

Os dados fornecidos pelo BNDES sobre o valor dos desembolsos destinados às principais construtoras brasileiras, nos últimos cinco anos, pela linha pós-embarque, demostram o volume e a concentração de recursos. De acordo com os dados, nota-se que entre 2009 a 2012, o número de empresas beneficiadas por esta linha de financiamento varia de 17 a 40 por ano. No geral, as construtoras estão nas primeiras posições quanto aos maiores valores de desembolso em todos os anos da amostra. As construtoras brasileiras unidas à Embraer são as destinatárias da maior parte dos desembolsos realizados pelo banco. A média de valores desembolsados nos cinco anos corresponde a aproximadamente US\$2,3 bi. Em 2013, o valor desembolsado as cinco principais construtoras, Camargo Corrêa, Andrade Gutierrez, Queiroz Galvão, OAS e Odebrecht, somadas a Embraer, corresponde a aproximadamente 95,7\% do valor total desembolsado para as 36 empresas beneficiadas naquele ano. Em 2012, aproximadamente 54,4\% do valor total que foi destinado as 40 empresas, foi destinado a Odebrecht, o que corresponde a aproximadamente a US\$ 1,19 bi. De 2009 a 2013, dos recursos destinados somente às cinco construtoras brasileiras citadas acima, a Odebrecht obteve ao menos 73,69\% do valor. (BNDES, $2014^{11}$ )

$\mathrm{O}$ apoio que o Brasil fornece às grandes construtoras através de financiamentos do BNDES, segundo Borges (2011), gera críticas por aqueles que acreditam que as grandes construtoras brasileiras não deveriam ter prioridades no empréstimo tendo em que vista que, já consolidadas nesse mercado, teriam acesso a financiamentos alternativos. Borges reafirma: "Novamente vem o dilema do governo financiar justamente as empresas que possuem maior capital em detrimento de outras possibilidades, ampliando a concentração do capital na mão de poucos” (Borges, 2011: 153). 
A resposta do BNDES para esta crítica é que para a natureza do financiamento proposto e para os países da América do Sul que são os clientes das construtoras no exterior, a afirmativa de que os financiamentos estão disponíveis não é verdadeira. Segundo Machado, superintendente da área de comércio exterior do BNDES, para os países, nos quais se enquadraram os da região sul-americana, ou seja, países com alto risco, de nível de desenvolvimento similar ou abaixo do Brasil, no qual prazos longos de financiamento são requeridos e, em que se trata de projetos de infraestrutura de grande porte como hidrelétricas, gasodutos e aquedutos, a situação de crédito é muito distinta da encontrada nos países desenvolvidos (Machado, informação verbal ${ }^{12}$ ). Assim, o caso dos países da América do Sul e África é apresentado como distinto, pois as empresas brasileiras embora possam ser consideradas grandes empresas e possuírem acesso a crédito, lembra-se que não é a empresa que é financiada, mas o cliente dessas empresas, ou seja, o governo ou a empresa privada. Para atuação nesses mercados, portanto, o financiamento internacional não seria abundante e o apoio do governo é necessário.

Nas negociações com o governo anfitrião ${ }^{13}$, vale destacar que para as empresas de engenharia e construção, a possibilidade de financiamento pelo BNDES é apresentado como um diferencial. A empresa OAS, por exemplo, na tentativa de ingressar no mercado do Paraguai, foi questionada sobre as possibilidades de financiamento utilizadas pela empresa, a qual respondeu que, em geral, as obras na região contam com o apoio do BNDES (Brasemb Assunção Recebido em 17/10/2011 ${ }^{14}$ ).

Do mesmo modo, um informe da embaixada do Brasil, em Buenos Aires, atesta a importância do BNDES no financiamento de obras de infraestrutura na Argentina, mediante a seguinte afirmativa: “Tendo em vista as restrições atualmente enfrentadas pela Argentina na obtenção de crédito, é evidente a importância dos financiamentos que vêm sendo concedidos pelo BNDES para a aquisição de bens e serviços de alto valor agregado. (Brasemb Buenos Aires Recebido em: 13/12/2010 ${ }^{15}$ ).

O caso da Argentina ilustra a importância do financiamento do BNDES. Das contratações referentes aos desembolsos no apoio à exportação pelo BNDES, na modalidade pós-embarque, no período de janeiro de 1998 a março de 2013, considerando-se somente as obras de infraestrutura na América do Sul, tem-se que das 35 obras que contaram com financiamento do BNDES, 12 foram destinadas a obras na Argentina cujo desembolso de realizou no período de 2005 a 2012 (BNDES ${ }^{16}$ ). Nota-se, também que os desembolsos ocorreram para projetos realizados principalmente na Argentina, Venezuela e Peru. Paralelamente, estes são os três países em que mais atuam as construtoras brasileiras.

Deve-se atentar, no entanto, para a afirmativa de Borges (2012) ao relatar que muitas promessas da diplomacia brasileira, quanto ao crédito do BNDES, só se concretizaram no caso das construtoras brasileiras. Nas demais iniciativas, o crédito, na maioria das vezes, não se concretizou, 
gerando reações adversas que questionaram a influência do Brasil nos países vizinhos. Assim, os conflitos e divergências da atuação das empresas geram ambiguidade. Por um lado, o discurso político e econômico entre os Estados se aproxima, mas, por outro lado, gera resistências internas no modo como o Brasil se projeta, tendo como base os desequilíbrios comerciais e econômicos.

No segundo ponto, com relação ao apoio do corpo diplomático, a forma como a diplomacia tradicional brasileira, através de suas embaixadas e consulados atua, complementa o posicionamento do Brasil perante o tema. Assim, não menos importante, mas pelo seu caráter subjetivo, difícil de ser mensurado, coloca-se o apoio diplomático na exportação de serviços brasileiros.

A política realizada pelos agentes do governo, em favor das empresas, é expressa, em especial, pela atuação e pelas iniciativas das embaixadas. Vernon (1980) relata que as embaixadas dos países industrializados realizam um trabalho de apoio, promoção e proteção às empresas, em especial, quando estas solicitam o apoio para as suas subsidiárias. O modo como cada governo promove esse apoio varia e abarca questões de influência política e de orientação. No caso do governo brasileiro e suas empreiteiras, verificase que as embaixadas executam o apoio fomentando diversas iniciativas como realizar contatos com o Setor de Promoção Comercial do Ministério das Relações Exteriores; acompanha o Investimento Externo Direto por setor; realiza eventos para promover a engenharia do Brasil e expor o âmbito de atuação do BNDES; facilitar o acesso a informações sobre oportunidades de negócios e facilita contatos; agenda audiências com autoridades do país anfitrião, dentre outras.

Na Bolívia, por exemplo, uma das iniciativas para promover a engenharia brasileira foi a realização de evento, especificamente com este intuito, ocorrido em março de 2003, no espaço cultural da embaixada. Neste evento, realizado pela embaixada brasileira em La Paz, em parceria com a Câmara de Comércio Brasil-Bolívia, houve a apresentação do vídeo “Engenharia do Brasil” preparado pela Andrade Gutierrez, a Bardela, a Camargo Correa, a Norberto Odebrecht e a Queiroz-Galvão. Na ocasião houve a indagação pela Câmara de Comércio Brasil-Bolívia sobre a possibilidade de um evento semelhante sobre o BNDES ${ }^{17}$. Evento similar ocorreu, também, em 2004 com a exibição do DVD "Engenharia Brasileira: Excelência Global”18.

Além de eventos como os citados acima, a embaixada facilita contatos com representantes de órgãos do governo, age como intermediador em negociações e informa sobre projetos e demandas existentes no país. $\mathrm{O}$ Itamaraty possui um setor específico para tratar da promoção comercial Setor de Promoção Comercial do Ministério das Relações Exteriores (SECOM). Os SECOM's são uma extensão do Departamento de Promoção Comercial e Investimentos do Itamaraty, situados em locais onde estão embaixadas e consulados brasileiros. Em detalhes, este setor é responsável 
por coletar e divulgar informações sobre oportunidades de negócios, apoiar o processo de internacionalização de empresas brasileiras, elaborar propostas que possam facilitar sua inserção e presença nos mercados externos, realizar eventos para promover a imagem do Brasil, realizar pesquisa de mercados, entre outras funções correlacionadas.

Assim, a diplomacia brasileira fornece o apoio necessário para concretizar a relação entre as construtoras brasileiras e os Estados estrangeiros. As empresas, por sua vez, constituem um elo político fundamental para os interesses brasileiros entre os quais a liderança no processo de integração regional.

De acordo com o vice-presidente de operações da Odebrecht, em entrevista a Folha de São Paulo ${ }^{19}$, a diplomacia brasileira facilita o diálogo no exterior e toda a ação da empresa na arena internacional está consoante com a política externa brasileira. De fato, a forma de diplomacia tradicional brasileira, através de suas embaixadas e consulados, revela o posicionamento do Brasil perante o tema.

Strange (1988; 1992) analisa a diplomacia triangular, em especial, na perspectiva dos Estados em desenvolvimento que recebem ou disputam os investimentos das empresas estrangeiras oriundas de países mais desenvolvidos. Destaca-se que a perspectiva adotada nessa pesquisa é distinta, pois parte do incentivo dado pelos Estados em desenvolvimento, no caso o Brasil, para que as empresas de sua nacionalidade se aloquem nos territórios de outros países.

Pode-se afirmar que o contexto atual impõe que se pense a diplomacia de países em desenvolvimento e de suas empresas, no sentido de impulsionar esta dinâmica. Esta dinâmica gera um poder de produção estrutural e, nesse sentido, o poder deriva da capacidade do Estado de agir como um bom investidor. Quando o Estado fornece subsídios para que as empresas se internacionalizem e se aloquem em outros territórios, a competição está em outro nível e é implícita. A ideia de prosperidade significa poder e implica na formação de aliança entre os Estados como se fossem países sócios. Como afirma Strange, o poder em economia política é percebido na forma como distribui seus custos e benefícios, bem como riscos e oportunidades, para os grupos sociais e para as empresas.

O sucesso no objetivo, no entanto, é determinado pelo sucesso das interações que ocorrem nas três dimensões (Estado-Estado, Estado-empresa e empresa-empresa). O Estado perde poder caso não se adapte ao jogo da negociação triangular. Em geral, a tendência é que as empresas sigam, por questões políticas, as orientações do Estado de origem, ainda que não haja nada nenhuma norma que a obrigue a proceder dessa forma. Visualizase, no entanto, a formação institucional para amparar as negociações das empresas no mercado externo. O Itamaraty compartilha do posicionamento de que impulsionar as empresas brasileiras intensifica as relações bilaterais e que a América do Sul é região prioritária para a política externa brasileira. 
A expansão das empresas brasileiras atende aos interesses do Brasil, tais como o retorno de divisas e a promoção comercial com vistas à expansão do soft power.

Considerando a política externa brasileira, as empresas apontam que o cenário mais favorável para a sua atuação no exterior são países onde há uma geopolítica brasileira forte, ou seja, uma presença diplomática e política forte, com mediação inclusive do chefe de Estado, se necessária. Dessa forma, evidencia-se a necessidade do apoio do governo brasileiro e de uma articulação com a política externa. De forma complementar, as construtoras brasileiras passam a ser parte integrante dos objetivos nacionais, o que justifica os mecanismos de apoio direcionados ao setor.

\section{Consideraçoes finais}

A promoção das empresas de engenharia não é uma estratégia do governo por si só. Internamente, as empresas pressionam para que o apoio exista, inclusive, enquanto objetivo de política externa. No momento, no entanto, deve-se destacar que o Brasil busca fazer com que suas empresas passem a atuar com o apoio do governo brasileiro. Antes, este apoio se fazia analisando-se caso a caso, sem que houvesse uma estratégica para o continente. Atualmente, o Brasil tem uma estratégia para a América do Sul e para as empresas brasileiras, mas é preciso analisá-la como um jogo de interesses e atores, cujo alinhamento de ideias e práticas nem sempre ocorrem.

A relação entre as empresas brasileiras de construção, o Estado brasileiro e o governo anfitrião, no contexto da integração sul-americana, não se constrói sem que o lobby, interesses e contradições estejam presentes. O processo de integração regional é um fator de impulsão para que se realize a diplomacia brasileira por meio das construtoras. Esta relação é uma disputa por espaço político, no qual as empresas passam a influir nas relações de poder.

Diante das considerações apresentadas deve-se ressaltar que a relação entre desenvolvimento e política externa na história brasileira é muito mais complexa do que pode aparentar. Ao se destacar os períodos selecionados têm-se como parâmetro a utilização da metodologia de Max Weber dos tipos ideais, trazendo a superfície os aspectos mais marcantes de cada período, mas com a consciência de que na realidade o "tipo puro" se confronta com a diversidade de formas e conteúdo.

Ao incorporar a internacionalização de empresas na política externa brasileira, coloca-se como desafio convergir os interesses internos com a projeção no cenário internacional. No novo desenvolvimentismo, o conceito de desenvolvimento é retomado de forma ampliada e carrega consigo a premissa da junção do nacional com o processo de internacionalização. O Estado é o agente principal da política externa, mas incentiva outros atores 
a exercerem a diplomacia. Busca aliar o Itamaraty com a elite empresarial e, sobretudo, movimentar os aparatos burocráticos na consecução do objetivo. Assim, destacam-se os agentes econômicos, em especial, as empresas transnacionais e os bancos públicos.

A forma como o Estado vai sanar as dificuldades da internacionalização, promovendo políticas públicas que incentivem o processo depende do modelo político adotado pelo Estado. Dois modelos se destacam. Em um deles, o Estado é visto como indutor do processo, no outro, como facilitador. A diferença é que no primeiro há intervenção ativa do Estado no processo de internacionalização, elegendo setores estratégicos de atuação. No segundo caso, visa-se criar marcos regulatórios favoráveis à internacionalização sem definir qualquer setor como estratégico.

Na atualidade, acredita-se que, o Estado brasileiro atue mais como indutor do que como facilitador do processo. Com o apoio das políticas de financiamento do BNDES, com a aprovação da Política Industrial, Tecnológica e de Comércio Exterior (PITCE) em 2003 e a aprovação da Política de Desenvolvimento Produtivo (PDP) em 2008 e uma política diplomática atuante, o governo brasileiro demonstra que elegeu os seus setores estratégicos e atua para promovê-los. O setor de engenharia e construção está entre eles. Na fase inicial da internacionalização (1970 a 1990), o Estado teria agido como facilitador.

Assim, a promoção do setor de serviços de engenharia pode ser compreendida como forma de fomentar as relações entre os países e de expansão de influência, em que a integração regional é um caminho para desenvolvimento nacional. Ressalta-se, no entanto, que embora o discurso econômico-comercial de cooperação perpasse a premissa de uma política solidária e humana, os interesses políticos envolvem o acesso a mercados, vantagens econômicas e influência em foros multilaterais.

A política estratégica realizada por intermédio das empresas do Brasil revela uma política branda de interesses e os desafios da conjuntura sulamericana. A presença das construtoras é uma disputa de espaço geopolíticoeconômico. É isto que está em pauta e é isto que as torna estratégicas para o governo brasileiro. No contexto de integração de infraestrutura sul-americano, as construtoras aparecem como elemento de destaque. Apesar das contradições e possíveis conflitos, a internacionalização das empresas corresponde a uma estratégia do Brasil para se projetar regionalmente e internacionalmente, o que insere uma nova perspectiva na relação do Brasil com os países da América do Sul. 


\section{Notas}

${ }^{1}$ Adota-se o conceito de empresa transnacional proposto pela UNCTAD, segundo a qual, a” Empresa Transnacional (ETN) é geralmente considerada como uma empresa que compreende as entidades em mais de um país que operam sob um sistema de tomada de decisão que permite políticas coerentes e de uma estratégia comum. As entidades são tão ligadas, por posse ou não, que uma ou mais delas podem ser capazes de exercer uma influência significativa sobre os outros e, em particular, partilhar conhecimentos, recursos e responsabilidades com os outros” (UNTCTAD, tradução livre).

${ }^{2}$ O conceito de diplomacia tríade é utilizado por Strange (1988; 1992). Por diplomacia tríade entende-se a relação que se estabelece entre as três formas de diplomacia: a diplomacia governo-governo, a governo-empresa e a empresa-empresa. Na diplomacia Estados-empresa, as empresas são capazes de influenciar nas negociações e tomadas de decisões em assuntos que antes eram vistos como um campo específico das relações entre Estados. A relação Estado-empresa torna-se, para ambos os lados, uma estratégia política para o desenvolvimento econômico global.

${ }^{3}$ Ricupero, Rubens. Entrevista. Realizada em 11/12/2013.

${ }^{4}$ Coutinho, Luciano; Reichstul, H.P. Tendência do Investimento Empresarial do Estado Brasileiro. Clasco - FUNDAP - 1979 (mimeo).

${ }^{5}$ Ver: Ferraz Filho (1981); Viégas (2009); Fares (2007).

${ }^{6}$ Ver: Fares (2007); Campos (2008).

${ }^{7}$ Os contratos counter-trade ou sistema barter funcionavam da seguinte forma: o governo brasileiro pagava a empresa em moeda e o governo estrangeiro pagava o governo brasileiro fornecendo petróleo. No caso, em outras palavras, o Brasil pagava o petróleo com prestação de serviços e mercadorias.

${ }^{8}$ Atualmente, há uma preleção pelo termo transnacional em decorrência de multinacional (Kucinski, 1981). A expressão multinacional carrega uma carga pejorativa e transmite a ideia errônea de ser composta por varias nações, desvinculando-se de seu caráter nacional, o que não se mostrou verdadeiro. Em parte seu caráter pejorativo é fruto da condição ideológica de mascarar a sua nacionalidade ou origem utilizando-se de artifícios para explorar o mercado externo (Carvalho Filho, 2011). O termo transnacional, por sua vez, elucida a atuação em mais de um país desvinculando-se de juízos de valor e não transmitindo a falsa de noção de serem empresas apátridas. Ver: Kucinski, Bernardo. O que são multinacionais. SP: Brasiliense, 1981; Carvalho Filho, José Carlos de. "O Brasil e as Empresas Transnacionais: os Novos Rumos para a Transnacionalização das Empresas Nacionais”. Scientia Iuris, Londrina, v. 15, n. 1, p. 89-104, jun. 2011.

9 Pressão indígena faz Odebrecht desistir de hidrelétrica no Peru. Valor Econômico, 25/11/2011. Disponível em: http://www.valor.com.br/internacional/1110222/pressaoindigena-faz-odebrecht-desistir-de-hidreletrica-no-peru. Consultado em: março de 2012.

${ }^{10}$ ] O setor de exportação de serviços, em países desenvolvidos, corresponde a aproximadamente $80 \%$ do PIB ou até $40 \%$ das exportações. Ver: Santos, Fabiano. "Poder 
Legislativo, Exportação de Serviços e seus Benefícios para o Desenvolvimento Econômico". In: Integração Regional, Exportação de Serviços e Desenvolvimento Econômico no Brasil. Cadernos Necon, 2006. No Brasil, dados divulgados pelo IBGE apontam que em 2013 o setor de serviços correspondeu a aproximadamente $70 \%$ do PIB brasileiro.

${ }^{11}$ Desembolsos Pós-Embarque por Empresa Exportadora. Fonte: BNDES.

${ }^{12}$ Machado, Luciene. Entrevista. Realizada em 30/11/2014.

${ }^{13}$ ] Entende-se por governo anfitrião, o Estado no qual se realizará o empreendimento.

${ }^{14}$ Correspondência diplomática. Brasemb Assunção para Exteriores em 17/10/2011. Fonte: Arquivos do Itamaraty.

15 Correspondência diplomática. Brasemb Buenos Aires para Exteriores em 11/12/ 2010.Fonte: Arquivos do Itamaraty.

${ }^{16}$ ] Contratações referentes a desembolsos no apoio à exportação pelo BNDES - Pósembarque (janeiro de 1998 a março de 2013). Fonte: BNDES

${ }^{17}$ Correspondência Diplomática. Brasemb La Paz. Recebido em: 02/04/2003. Fonte: Arquivos do Itamaraty.

${ }^{18}$ Correspondência Diplomática. Brasemb La Paz. Recebido em: 20/09/2004. Fonte: Arquivos do Itamaraty

19 Diplomacia brasileira ajudou empreiteiras. Segredos do Itamaraty - Folha Transparência. 18/09/2011. Disponível em: http://www1.folha.uol.com.br/fsp/mercado/me1809201107.htm? Consultado em 15/09/2012 


\section{Bibliografía}

Attuch, Leonardo; Mendes, Murilo (2008), Quebra de Contrato: o Pesadelo dos Brasileiros. Folium, $2^{\circ}$ edição, Belo Horizonte.

BNDES, Disponível em http://www.bndes.gov.br/

Borges, Fábio (2011), As relações do Brasil com os países Amazônicos nos governos de Fernando Henrique Cardoso e Lula (1995-2010): possibilidades e problemas do regionalismo aberto. Tese de Doutorado em Sociologia apresentado ao Departamento de Pós-graduação em Sociologia na Faculdade de Ciências e Letras de Araraquara (FCLAr), da Universidade Estadual Paulista (UNESP).

Idem (2012), “As relações do Brasil com os países sul-americanos nos governos de Fernando Henrique Cardoso e Lula (1995-2010): "hegemonia consensual” e seus limites”, Monções, Revista de Relações Internacionais da UFGD, v.1, n.2, jul.dez.

Campos, Pedro H. P. (2010), “A transnacionalização das empreiteiras brasileiras e o pensamento de Ruy Mauro Marini”. III Conferência Internacional em História Econômica \& V Encontro de Pós-Graduação em História Econômica, Brasília.

Idem (2008), “As origens da internacionalização das empresas de engenharia brasileiras”. XIII Encontro de História - ANPUH, Apresentação no Simpósio Temático - Estado, Poder e Economia do Brasil dos séculos XIX e XX, Rio de Janeiro..

Cardoso, Sandra Aparecida; Miyamoto, Shiguenoli (2012), “A política externa dos governos Geisel e Lula: similitudes e diferenças”. Revista de Economia \& Relações Internacionais, vol.11 (21), julho, 2012.

Carvalho, Clarissa B. R. P (2011), A atuação do BNDES na integração da América do Sul. Dissertação de mestrado apresentada ao Programa de Ciência Política da Universidade Federal de Pernambuco como requisito parcial à obtenção do título de Mestre em Ciência Política. Recife.

Caseiro, Luiz Carlos Zalaf (2013), Novas Estratégicas de Internacionalização de Empresas Brasileiras: expansão geográfica, determinantes e alternativas de política industrial. Dissertação apresentada ao Departamento de Sociologia da Faculdade de Filosofia, Letras e Ciências Humanas da Universidade de São Paulo para a obtenção do título de Mestre em Sociologia, São Paulo.

Catermol, Fabrício (2005), “BNDES - Exim: 15 Anos de Apoio às Exportações Brasileiras”. Revista do BNDES, Rio de Janeiro, v. 12, n. 24, p. 3-30, dez. 2005. 
Cervo, Amado Luiz (2008), Inserção Internacional: formação dos conceitos brasileiros. Saraiva, São Paulo.

Idem (2009), A internacionalização da Economia Brasileira. Editora Thesaurus.

Couto, Leandro Freitas (2010), “Neo-desenvolvimentismo X estado logístico”. Minha Circunstância (blog); 09/03/2010. Disponível em $<$ www.desenvolvimentistas.com.br>. Consultado em 20/05/2012.

Fares, Seme Taleb (2007), O Pragmatismo do Petróleo: as relações entre o Brasil e o Iraque de 1973 a 2007. Dissertação apresentada ao Programa de Pós Graduação em Relações Internacionais da Universidade de Brasília como requisito parcial para obtenção do titulo de mestre em Relações Internacionais, Brasília.

Ferraz Filho, Galeno Tinoco (1981), A Transnacionalização da Grande Engenharia Brasileira. Dissertação de Mestrado apresentada ao Departamento de Economia e Planejamento Econômico do Instituto de Filosofia e Ciências Humanas da Universidade Estadual de Campinas, Campinas.

Fiocca, Demian (2006), “O BNDES e a Internacionalização das Empresas Brasileiras”. Apresentação no Seminário “As Novas Multinacionais Brasileiras”, FIRJAN, Rio de Janeiro, 29/05/2006. Disponível em: <http:/ /www.bndes.gov.br/SiteBNDES/export/sites/default/bndes_pt/Galerias/ A r quivos / e m presa/d o w n lo a d/a p resentacoes / apresentacao_fiocca_firjan.pdf>. Consultado em 14/01/2012.

Gilpin, Robert (2002), A Economia Política das Relações Internacionais. Universidade de Brasília, Brasília.

Iglesias, Roberto Magno; Veiga, Pedro da Motta (2002), "Promoção de Exportações via Internacionalização das Firmas de Capital Brasileiro” In: Pinheiro, Armando Castelar; Markwald, Ricardo; e Pereira, Lia Valls (orgs). O Desafio das Exportações. BNDES, $1^{\text {a }}$ edição, Rio de Janeiro.

Novoa, Luís Fernando (2009), “O Brasil e seu “desdobramento”: o papel do BNDES na expansão das empresas transnacionais brasileiras na América do Sul”. In: Instituto Rosa Luxemburg Stiffung et (org.), Empresas Transnacionais Brasileiras na América Latina: um debate necessário. Expressão Popular, São Paulo.

Oliva, Aloizio Mercadante (2010), As Bases do Novo Desenvolvimentismo no Brasil: Análise do Governo Lula (2003-2010). Tese de doutorado apresentada ao Instituto de Economia da UNICAMP para a obtenção do título de Doutor em Ciências Econômicas. Campinas-SP.

Ribeiro, Fernando J; Lima, Raquel Casado (2008), Investimentos Brasileiros na América do Sul: Desempenho, Estratégias e Políticas - Relatório Final. 
Disponível em: ? http://www.iadb.org/intal/intalcdi/PE/2008/02012.pdf ?. Consultado em 10/09/2012.

Sennes, Ricardo Ubiraci [et al.] (2007), A agenda de interesses empresariais brasileiros na América do Sul: o setor de serviços. CNI, Brasília.

Sicsú, João; Paula, Luiz Fernando de; Michel, Renaut (2007), “Por que novo-desenvolvimentismo?” Revista de Economia Política, vol. 27, n ${ }^{\circ} 4$ (108), pp. 507-524 outubro-dezembro/2007.

Strange, Susan (1988), States and Markets - an introduction to international political economy. B Blackwell, New york.

Idem (1992), “States, firms and diplomacy”. International Affairs 68;1 (1992), 1-15.

Tastsch, Luisa Bertuol, (2011), A política externa do Governo Lula: um novo pragmatismo responsável?. Dissertação apresentada como exigência para conclusão do curso de Pós-Graduação em Ciência Política da Universidade Federal do Rio Grande do Sul. Porto Alegre.

Toni, Jackson de (2013), Novos Arranjos Institucionais na Política Industrial do Governo Lula: a Força das Novas Ideias e dos Empreendedores Políticos. Tese apresentada como requisito parcial para a obtenção do Título de Doutor em Ciência Política pelo Programa de Pós-Graduação em Ciência Política da Universidade de Brasília. Brasília.

Vernon, Raymond (1980), Tempestade sobre as multinacionais. Zahar Editores.

Viégas, João R.R (2009), A Internacionalização privada na onda estatizante: as relações publico-privadas na internacionalização das empreiteiras brasileiras entre 1974 a 1979. Dissertação apresentada como requisito parcial para a obtenção do Título de Mestre, ao Programa de Pós Graduação em História, da Universidade do Estado do Rio de Janeiro, Rio de Janeiro.

Vigevani, Tullo; Cepaluni, Gabriel (2007), “A Política Externa de Lula da Silva: A Estratégia da Autonomia pela Diversificação”. Contexto Internacional, Rio de Janeiro, vol. 29, n 2, julho/dezembro 2007, p. 273-335.

Recibido: 20.11.2014

Aceptado: 10.12.2014 